and argues that currently available information about interventions that actually improve health should be used to help disadvantaged populations now rather than waiting for radical social change. Catchatoor, in an update on the Health Inequalities Research Collaboration, describes how action is being taken at the national level to build the evidence base.

The papers by Turrell and Harding remind us that we need to see any action to tackle health inequalities in the wider social context of income distribution, employment, community infrastructure and global forces. As big as the health system is, it still plays only a small part in the overall solutions. Turrell emphasises the need for action on upstream, midstream and downstream influences on health. Harding, in a sequel to a paper published in the Bulletin last year (Volume 12, Number 5), reminds us that all data sources must be scrutinised carefully.

As our thinking shifts from defining and describing the patterns of health inequality to acting to reduce inequalities, it is important to recognise that doing our 'core business' well and in a way that effectively addresses health inequality is an important contribution to creating a more equal Australian society. The NSW Health and
Equity Statement is a local example of how the priorities of health services are being defined to reduce inequality. ${ }^{7}$

\section{REFERENCES}

1. Australian Institute of Health and Welfare. Health Expenditure No 17. Canberra: AIHW, 2000.

2. King L, Whitecross P. A Health Promotion Perspective: not enough to make you well. Harris E, Sainsbury P, Nutbeam D (editors). Perspectives on Health Inequality. Sydney: Australian Centre for Health Promotion, 2000.

3. Commonwealth Department of Health and Aged Care. Better Health Care-Studies in the successful delivery of health care services for Aboriginal and Torres Strait Islander Australians. Canberra: CDHAC, 2001. Catalogue no. 2942.

4. Carriage C, Harris E, Kristensen E. Evaluation of the first Aboriginal Health Strategic Plan in South Western Sydney. Australian Health Services Review 2000: 23(3): 20-27.

5. National Health Service, Research and Development Strategic Review. Strategic Review Primary Care-Report of the Topic Working Group. London: National Health Service, 1999.

6. Sergerie D, Farley C. The relevance of social inequalities for designing intervention programs. Injury Control and Safety Promotion 2001; 8(3): 155-161.

7. Hyde J. Tackling health inequalities in the NSW Health System: The NSW Heath and Equity Statement. NSW Public Health Bulletin 2001; 12(7): 192-193. 哭

\title{
HOW CAN PRIMARY CARE INCREASE EQUITY IN HEALTH?
}

\section{Mark Harris}

School of Community Medicine

University of New South Wales

\section{John Furler}

Department of General Practice

University of Melbourne

\section{BACKGROUND}

A number of comparative studies have demonstrated an association between the provision of primary care in developed countries and favourable markers of health status. ${ }^{1,2}$ There is also evidence for an association between health-care systems that are organised around a strong primary-care sector and reduced health inequalities. ${ }^{3}$ Because they reach so much of the population, primary care services such as general practice have an opportunity to address health inequities by improving access to quality care: for example, by providing better anticipatory or preventive care within primary care services themselves, and by outreach into disadvantaged communities. However, to be most effective, these need to be integrated with other multilevel community-based strategies that address the social and economic determinants of health.

\section{ACCESS}

Tudor Hart, working as a general practitioner in Wales, first described the 'inverse care law' in which those with the greatest need access health services the least. ${ }^{4}$ This applies both to access to primary care services and access to those services that occur subsequent to first contact. In Australia, the evidence for disparities in access to primary care is most apparent in relation to primary, secondary, and tertiary preventive care services. People who are socioeconomically disadvantaged are more likely to need, but are less likely to use, preventive health services such as dentists, immunisation, and cancer screening tests. ${ }^{5}$

For example, single parent and migrant families - and families where the parents are unemployed, on low income, or have low levels of education - are at risk of low levels of age-appropriate immunisation..$^{6,7}$ There is evidence to suggest that women of low socioeconomic status are less likely to have attended health services for a Pap smear, although women living in low socioeconomic areas have a higher incidence of cervical cancer. ${ }^{8,9,10}$ This lack of anticipatory care, leading to more crisis management in health, is most evident for indigenous Australians. ${ }^{11,12}$ 
Access to health care services in Australia is mediated by a number of factors:

- geographic availability of services, especially in rural and outer urban areas; ${ }^{13}$

- cost of health care services, especially services to which patients are referred from primary care (for example: allied health, medical specialists, private health care); and cost of treatments (for example, prescribed drugs) including 'co-payments' on top of Medicare and the Pharmaceutical Benefits Scheme. An extreme example of restricted access to care is found in the case of asylum seekers who may be without access to primary or hospital care; ${ }^{14}$

- waiting times for publicly-funded health services, especially allied health services, outpatient medical specialist services, and elective procedures;

- conscious and unconscious barriers to disadvantaged groups, including cultural and language barriers, which may apply at both the practitioner and the patient level.

One strategy to deal with this disparity in access is to target disadvantaged communities and populations with specific health programs and services. While this may work in the short-term, as commitment wanes it may be more difficult to sustain when compared to 'mainstream' programs and services. There is also a potential for stigmatisation. On the other hand, ensuring mainstream services are distributed according to clearly-defined need can assist in ensuring fair access.

\section{QUALITY OF CARE}

Disadvantaged groups need not only to access health care services but also for these to be of comparable quality. Subtle and unconscious factors may affect the way in which health care is provided to disadvantaged groups. For example, in primary care we have found differences in the way in which general practitioners (GPs) respond to patients with anxiety or depression - being more likely to prescribe to, and less likely to refer or offer nonpharmacological interventions for, unemployed patients. ${ }^{15}$ GPs may spend less time in consultations with socioeconomically disadvantaged patients. ${ }^{16,17,18}$ Other studies have shown socioeconomic differentials in the use of allied health services, waiting times in emergency departments, ${ }^{19}$ and referral for investigations such as angiography. ${ }^{20}$

Systematically addressing the financial, structural, and attitudinal barriers to more equitable quality health care requires more than education for service providers. A key strategy in improving equity and quality of care is, therefore, to carefully examine patterns of service provision. For this to be possible, socioeconomic data needs to be routinely recorded and analysed. ${ }^{21}$ This seems particularly challenging in primary care. While practitioners are often comfortable in being sensitive to gender or ethnicity in their work, being sensitive to social disadvantage appears to have less legitimacy. ${ }^{22}$

\section{SPECIFIC INTERVENTIONS IN PRIMARY CARE TO REDUCE HEALTH INEQUALITIES}

Strategies that have been shown to be effective in reducing health inequalities include outreaching services, reducing cost and other barriers to access, developing culturallyappropriate services, and increasing access to skills and resources that will enable people to adopt more healthpromoting lifestyles. ${ }^{23,24}$ A number of divisions of general practice have developed programs that attempt to improve access for socioeconomically disadvantaged groups, through direct provision of allied health services and raising community awareness of the need to access GPs for preventive care. ${ }^{25}$ Targeted community-based preventive or outreach programs are effective in reducing behavioural risk factors and improving preventive health care. ${ }^{26,27}$ Outreach programs have achieved improved health outcomes for disadvantaged groups such as homeless people. ${ }^{28}$ As part of a holistic approach to family support, home visiting has been shown to minimise the risks of child abuse and neglect. ${ }^{29}$

Approaches to improving the health of disadvantaged communities are most effective when they are tailored to the needs of those communities, involve local communities, and provide services in ways that increase their accessibility. ${ }^{30,31}$ Developing relationships within communities takes time and often needs to start by addressing priority issues identified by the community. These may not be the same issues as identified by local service providers. A study to identify factors that enhanced the capacity of divisions of general practice to develop diabetes programs with indigenous communities found that having a population rather than a patient approach, an active involvement of local community controlled health services or community organisations, and a willingness to move at the pace set by the community, were key features of successful programs. ${ }^{32}$

\section{SYSTEMIC CHANGE}

Multilevel strategies are more effective than single strategies. In patients with health problems, this includes building systematic approaches to health care within primary care; building linkages between primary care and specialist services; and developing community awareness, health literacy, and self management skills. ${ }^{33,34}$ In the United States, a number of studies have found that, when compared with services that are less well-integrated or specialist-oriented, there is an association between the provision of more 'holistic' and proactive communitybased health care services and improved health outcomes at lower cost. ${ }^{35,36,37}$

Underpinning this, we need a system that is oriented to the needs of populations and communities, and in which 
the various elements of primary care-especially general practice and community health-work more effectively together and counterbalance pressure from hospitals, which dominate the health care system in all states and territories. We are a long way from this at present; however, positive developments include:

- establishment of integrative structures at the local level (primary care partnerships in Victoria and primary care networks in NSW);

- various trials and examples of co-location or integrated service delivery between GPs and community health services;

- joint planning and provision of allied health services by some rural divisions of general practice and rural area health services;

- development of some integrated care programs for chronic disease that are focused on the community services rather than on hospital services.

\section{CONCLUSIONS}

Primary care can make a major contribution to reducing health inequalities. To do this, it needs to identify and address barriers to access and quality of care for disadvantaged population groups and communities. It also requires systemic change to underpin more specific interventions to provide outreach or targeted preventive services and to build the capacity of individuals and communities.

\section{REFERENCES}

1. Starfield B. Primary care: is it essential? Lancet 1994; 344 : 1129-1133.

2. Shi L, Starfield B, Kennedy BP, Kawachi I. Income inequality, primary care and health indicators. J of Fam Pract 1999; 48(4): 275-284.

3. Starfield, B. Is strong primary care good for health outcomes? Griffen J (editor). The Future of Primary Care. London: Office of Health Economics, 1995.

4. Hart JT. The inverse care law. Lancet 1971; 1: 405-12.

5. Harris MF, Knowlden S. Clinical perspective: a general practitioner response of health differentials. Harris E, Sainsbury P, Nutbeam D (editors). Perspectives on Health Inequity. Sydney: Australian Centre for Health Promotion 1999; 73-82. ISBN 1864873132.

6. Bell JC, Whitehead P, Chey T, et al. The epidemiology of incomplete childhood immunisation: an analysis of reported immunisation status in western Sydney. $J$ Paediatr Child Health 1993; 28: 451-45.

7. Herceg A, Daley C, Schubert P, Hall R, Longbottom H. A population based survey of immunisation coverage in two year old children. Aust J Public Health 1995; 19(5): 465-470.

8. Shelley JM, Irwig LM, Simpson JM, Macaskill P. Who has pap smears in New South Wales? Patterns of screening across sociodemographic groups. Aust J Public Health 1994; 18: 406-411.

9. Armstrong BK, Rouse IL, Butler TL. Cervical cytology in Western Australia. Med J Aust 1986; 144: 239-247.
10. New South Wales Cancer Council. Cancer Council Cancer Maps for New South Wales. Variations by Local Government Area 1991-1995. Sydney: New South Wales Cancer Council, 1998.

11. Patel MS. Frequency of hospital admissions for bacterial infections among aboriginal people with diabetes in central Australia. Med J Aust; 155(4): 218-22.

12. Willis J. Fatal attraction: do high-technology treatments for end-stage renal disease benefit Aboriginal patients in central Australia? Aust J Public Health 1995; 19(6): 603-9.

13. Young AF, Dobson AJ, Byles JE. Access and equity in the provision of general practitioner services for women in Australia. Aust N Z J Public Health; 2000; 24: 474-80.

14. Harris M, Telfer B. The health needs of asylum seekers in the community. Med J Aust 2001; 175: 589-592.

15. Harris M, Silove D, Kehag E, Barratt A, Manicavasager V, Pan J, Frith JF, Blaszczynski A, Pond D. Anxiety and depression in general practice patients: prevalence and management. Med J Aust 1996; 164: 526-529.

16. Wiggers JH and Sanson-Fisher R. Duration of general practice consultations: associations with patient occupational and educational status. Soc Sci Med 1997; 44: 925-934.

17. Furler J, Harris E, Powell Davies G, Harris MF, Chondros P, Young D. The inverse care law revisited: Impact of disadvantaged location on GP consultation times. Med J Aust 2002. In press.

18. Stirling AM, Wilson P, McConnachie A. Deprivation, psychological distress, and consultation length in general practice. Br J Gen Pract; 2001; 51: 456-60.

19. Mohsin M, Bauman A, Ieraci S. Is there equity in emergency medical care? Waiting times and walk-outs in South Western Sydney hospital emergency departments. Australian Health Review; 1998; 21: 133-49.

20. Alter DA, Naylor CD, Austin P, Tu JV. Effects of socioeconomic status on access to invasive cardiac procedures and on mortality after acute myocardial infarction. New Engl JMed; 1999; 341: 1359-67.

21. Smeeth $L$ and Health $I$. Tackling health inequalities in primary care: recording socioeconomic data in primary care is essential. BMJ 1999; 318: 1020-1021.

22. Department of General Practice University of Melbourne, Department of Community Medicine University of Newcastle, Centre for Health Equity Training Research and Evaluation, Royal Australian College of General Practitioners. Action on health inequalities through general practice: Enhancing the role of the Royal Australian College of General Practitioners. Work in progress.

23. Gepkens A, Gunning-Schepers L. Interventions to reduce socioeconomic health differences: a review of the international literature. Eur J Public Health, 1996; 6: 218-226.

24. Turrell G, Oldenberg B, McGuffog I, Dent R. The Socioeconomic Determinants of Health: Towards a National Research Program and a policy and intervention agenda. Queensland University of Technology School of Public Health. Canberra: AusInfo, 1999.

25. Harris E, Traynor V, Rose V, Furler J, Davies PGP, Harris MF, Young D. Action of Health Inequalities: The role of divisions of general practice. Centre for General Practice Integration Studies. Sydney: University of New South Wales, 2001. 
26. Sowden A, Arblaster L. Community interventions for preventive smoking in young people. Cochrane database of systematic reviews 2000 www.cochrane.org.

27. Manee CL, Hemphill JC, Letran J. Screening clinics for the homeless: evaluating outcomes. J Community Health Nurs 1996; 13(3): 167-77.

28. Access Support and Evaluation Research Unit. Access to health care for homeless people: a guide to currently accepted practice. Melbourne: University of Melbourne, 1997.

29. Review of literature on early intervention and home visiting program evaluation Draft-Families First Framework. Sydney: Office of Children and Young People, NSW Cabinet Office, 2000.

30. NHS Centre for Reviews and Dissemination. Review of the effectiveness of health service interventions to reduce variations in health. York: University of York, 1995.

31. Macintyre S, Chalmers I, Horton R, Smith R. Using evidence to inform health policy: case study. BMJ 2001; 222-225.

32. Lee P, Rose V, Harris E, Bonney M. National Divisions Diabetes Program. Optional Module 1. Part A. Aboriginal and Torres Strait Islander Populations. Sydney: Centre for General Practice Integration Studies and Centre for Health Equity Training Research and Evaluation, 1999.

33. Oldenberg B, McGuffog ID, Turrell G. Socioeconomic determinants of health in Australia: policy responses and intervention options. MJA 2000; 172(10): 489-92.

34. Whitehead M. The concepts and principles of equity and health. Geneva: World Health Organization, Regional Office, 1990.

35. Browne G, Roberts J, Gefni A, Byrne C, Weir R, Majumdar $\mathrm{B}$, Watt $\mathrm{S}$. Economic evaluations of community based care: less from twelve studies in Ontario. Journal of Evaluation in Clinical Practice 1999; 5(4): 367-85.

36. Forrest C, Whelan EM. Primary care safety-net delivery sites in the United States. A comparison of community health centers, hospital outpatient departments and physicians' offices. JAMA 2000; 284: 2066-2083.

37. Wagner EH, Glascow RE, Davis C, Bonomi AE, Provost L, McCulloch D, Carver P, Sixta C. Quality improvement in chronic illness: a collaborative approach. Joint Commission Journal on Quality Improvement 2001; 27: 63-80. 即

\section{CAN THE FAMILIES FIRST INITIATIVE CONTRIBUTE TO REDUCING HEALTH INEQUALITIES?}

\section{Garth Alperstein}

Division of Population Health

Central Sydney Area Health Service

\section{Victor Nossar}

Department of Community Paediatrics

South Western Sydney Area Health Service

This article describes the ways in which Families Firsta coordinated strategy of the NSW Government that has increased the effectiveness of early intervention and prevention services in helping families to raise healthy and well adjusted children - can contribute to reducing health inequalities.

\section{CHILD HEALTH INEQUALITY TODAY}

Inequality of health outcomes continues to be a major (and potentially reversible) feature of the health of Australia's children. The health of children is particularly sensitive to their socioeconomic environment. This environment can diminish the potential of 'reactive' or 'clinical' services to reduce health inequalities in children.

In spite of this, there has been progress in reducing some health inequalities over the past century. In 1970, the gap in infant mortality between Aboriginal and non-Aboriginal children was approximately four-fold. In
1998 this gap had reduced to approximately three-fold, but there has been little change over the last decade. Almost every health indicator related to children and youth continues to reveal a significant gap between the Aboriginal and non-Aboriginal populations. ${ }^{1}$ However, in Australia, there is a dearth of health outcomes data for children and youth by other indicators of disadvantage such as family income, occupation of parent(s), and income distribution.

There are abundant data indicating the relationship between socioeconomic inequality and poor health outcomes; and of growing income inequality in Australia. $^{2}$ For example, the share of equivalent gross household income received by the bottom 10 per cent of Australians decreased from 7.44 per cent in 1986 to 7.35 per cent in 1996; and that received by the top 10 per cent increased from 13.7 per cent in 1986 to 14.96 per cent in 1996; also, there has been an increase in child poverty in Australia. ${ }^{3,4}$ Similar trends towards growing inequality have been even more clearly established between the developed and developing worlds. In the face of this, at best, unchanging income inequality - or, more probably, growing income inequality-how likely is it that the strategies underpinning Families First can reduce health and social inequalities? 